\title{
O PLANEJAMENTO DO DESENVOLVIMENTO NO BRASIL RECENTE NA VISÃO DE IGNÁCIO RANGEL
}

Fábio Leão

Diretor de Desenvolvimento e Projetos da Agência de Fomento de Alagoas S.A. - Desenvolve, Mestre em Desenvolvimento e Meio Ambiente (PRODEMA/UFAL),

Maceió, AL, Brasil.

RESUMO - O artigo procura discutir as ideias basilares do pensamento de Ignácio Rangel, no tocante às proposições de um modelo de desenvolvimento para o Brasil que rompa com o subdesenvolvimento persistente e histórico. Procuraremos mesclar seu pensamento com o de outros autores na busca de caminhos alternativos para atualizar suas propostas de um país diferente, com espaços para o planejamento e para modificações estruturais nas formas de poder e nas formas de organização produtiva da sociedade.

Palavras-chave: Ignácio Rangel; desenvolvimentismo; planejamento do Brasil.

\section{THE PLANNING OF DEVELOPMENT IN BRAZIL RECENT IN THE VISION OF IGNÁCIO RANGEL}

\begin{abstract}
The article seeks to discuss the basic ideas of Ignácio Rangel 's thinking about the propositions of a development model for Brazil that breaks with persistent and historical underdevelopment. We will try to merge their thinking with that of other authors in the search for alternative ways to update their proposals from a different country, with spaces for planning and for structural modifications in the forms of power and in the forms of productive organization of society.
\end{abstract}

Keywords: Ignácio Rangel; Developmentalism; Planning in Brazil.

\section{INTRODUÇÃO}

$\mathrm{O}$ artigo pretende discutir inicialmente o conceito de desenvolvimento na visão de Ignácio Rangel e listar suas características e categorias principais. Neste primeiro momento, discutiremos as categorias iniciais da dualidade básica na obra de Rangel e as origens de seu pensamento, notadamente o materialismo dialético histórico. Discutiremos também o processo de desenvolvimento e a perifericidade do Brasil com relação ao centro dinâmico do sistema capitalista. E finalizaremos com algumas reflexões acerca da ociosidade de recursos e as alternativas de anti-ociosidade.

A economia do projetamento é discutida como um caminho crítico a ser trilhado para a efetivação do processo de desenvolvimento. Seguiremos com a etapa que trabalhará a importância do planejamento para o desenvolvimento e a superação da pobreza. Discutiremos as principais categorias do desenvolvimento territorial, seus principais atores, lideranças locais e importância do protagonismo em todo o processo. Levantaremos a hipótese da importância histórica no processo de desenvolvimento na região, bem como sua cultura e suas organizações. Buscaremos evidenciar que o planejamento central impacta nas regiões e municípios, mas seu alcance é limitado ou minimizado quando o lócus do desenvolvimento 
não é levado em conta. Portanto, a convergência econômica, política e social, e os agentes indutores do desenvolvimento são fatores decisivos na evolução socioeconômica das regiões. Afinal, todo o desenvolvimento é localizado, mesmo sofrendo influência dos aspectos econômicos e políticos externos que invadem o dia a dia da população local. Faremos, ainda nesta etapa, uma análise breve do modelo de desenvolvimento dos "dois Ignácios": Rangel e Sachs. Os dois pensadores convergem em ideias em alguns aspectos que procuraremos evidenciar como forma de reforçar a importância do planejamento do desenvolvimento.

$\mathrm{Na}$ terceira etapa apresentaremos o conceito de desenvolvimentismo como alternativa para o rompimento com o subdesenvolvimento. No escopo do conceito serão evidenciadas as categorias que o constituem, como seu tempo histórico, sua localização e seus aspectos institucionais no desenvolvimento de longo prazo. É importante verificar se as instituições existentes reforçam o processo de desenvolvimento. A partir desta análise inicial pode-se fazer uma extrapolação para a necessidade de criação de novas instituições que se coadunem com o novo processo e o fortaleça. O caminho oposto seria de grande dificuldade para a implantação de um novo modelo de desenvolvimento. Afinal, não se pode construir o novo a partir da manutenção de instituições muitas vezes ultrapassadas e que não mais atendem a processos de inclusão e superação da pobreza, com crescimento econômico e distribuição de renda.

$\mathrm{Na}$ quarta seção faremos análise do papel do Estado na economia. As ideias de Mariana Mazzucato de um Estado novo, empreendedor, inovador e impulsionador do setor privado, alinham-se com as de Ignácio Rangel quando este propõe a criação de uma forma nova de Estado colaborativo com o setor privado.

Por fim, na conclusão discutiremos os principais pontos do artigo com foco no papel do planejamento estatal e na economia do projetamento de Ignácio Rangel, e faremos algumas reflexões sobre as condições existentes no Brasil para a implantação de uma forma nova de desenvolvimento e a validação do desenvolvimentismo.

\section{CARACTERÍSTICAS DO PENSAMENTO DE IGNACIO RANGEL ACERCA DO MODELO DE DESENVOLVIMENTO ECONÔMICO}

Neste primeiro centenário dos pensadores do Brasil Romulo Almeida e Ignacio Rangel, a ABDE (Associação Brasileira de Desenvolvimento) e o BNDES (Banco Nacional de Desenvolvimento Econômico e Social), promoveram em conjunto um curso sobre o planejamento do desenvolvimento. O momento do curso não poderia ser mais apropriado, visto que teve início no primeiro dia imediatamente posterior ao segundo mandato da presidente Dilma Rouseff. 
As discussões que se seguiram foram muito vibrantes por descortinar resquícios dos discursos de campanha dos candidatos e analisar - sob a ótica dos dois pensadores - a realidade presente e os possíveis caminhos futuros do Brasil. De certo que o caminho que o país havia tomado naquele exato momento não deixava alternativas para pensamentos diferentes; e qualquer tentativa nesse sentido poderia soar como se ainda estivéssemos em campanha. Os caminhos que a economia e a política brasileira tomaram em 2015, no entanto, nos colocaram novamente na condição de discussão dos aspectos estruturantes do pensamento de Ignacio Rangel e Romulo Almeida.

O processo de desenvolvimento apresenta-se como um objetivo a ser alcançado em determinado local, em um período de tempo, e demanda articulações amplas de toda a sociedade para mobilizar todos os seus recursos - levando em conta sua história e aspectos culturais - para alcançar as metas inicialmente propostas. Ora, se é assim, percebe-se que se trata de algo que tem uma conotação política forte e se funda no intervencionismo para o rompimento de uma situação presente que não suporte as demandas da maioria de sua população.

Vemos na obra de Rangel diversos aspectos que tocam o processo de desenvolvimento com as características deste processo de desenvolvimento. Pretendemos, portanto, mergulhar e iluminar algumas das principais categorias do pensamento rangeliano e contextualizá-las à luz do pensamento de outros autores - notadamente aqueles que tratam o desenvolvimento como um fenômeno multidisciplinar, necessariamente de longo curso, inclusivo e sustentável. Procuraremos também trazer as categorias do pensamento rangeliano ao tempo presente com o intuito de retirar de sua conta aquilo que não é estruturante e discutir os pontos ainda presentes na estrutura social, econômica e de poder do Brasil.

\section{IGNACIO RANGEL E A DUALIDADE BÁSICA DA ECONOMIA BRASILEIRA}

Ignacio Rangel foi um pensador do processo de desenvolvimento, não um teórico da dependência, um estruturalista ou um cepalino. Seu pensamento foi influenciado por Hegel, Smith e Lênin, além de Marx. Já percebemos daí que sua preocupação sempre foi com a construção do desenvolvimento e não com a análise da situação passada. Obviamente que sua influência marxista não retira de sua análise os processos anteriores da economia e da sociedade; no entanto, estas considerações não o colocavam em situação de paralisia ou de conformação com o status quo vigente.

O materialismo histórico e dialético, aliás, foi basilar em seu pensamento. Foi o que o ajudou a analisar a realidade, partindo do concreto ao real e propondo a ruptura com as situações de exclusão e incompletude do Brasil à época. A proposição de soluções a partir de então se configurou no socialismo científico proposto por Marx e Engels. 
Como um nacional-desenvolvimentista sempre pautou seus estudos e propostas no novo, a partir do que se tinha à mão dentro do próprio país; sem a restrição da dependência externa, mas sempre atento a formas de superá-la com a mobilização dos recursos internos.

Sobre seu método de análise da realidade, Maria Malta é bastante didática ao afirmar:

\begin{abstract}
Não se poderia encontrar um método mais marxista autêntico no sentido de preocupar-se em ser materialista, histórico e dialético. Materialista, por jamais perder o concreto como ponto de partida e de retorno do processo de compreensão; histórico, por poder perceber como as especificidades históricas vão influenciar as trajetórias de desenvolvimento; e dialético, por se preocupar com todas as contradições presentes como constituintes do movimento do todo. (MALTA, 2014).
\end{abstract}

A despeito disso, Rangel não foi compreendido em seu tempo a partir de sua proposta de análise da realidade braseira, considerada como original por diversos pensadores do Brasil, como Maria da Conceição Tavares, Maria Malta e outros. Ao contrário, foi considerado um determinista e um dualista, e nada dialético.

Sua Teoria da Dualidade Básica se apresentava representada por dois pólos da economia brasileira, um pólo interno e um pólo externo. Cada um dos pólos apresentava dois lados, um interno e outro externo, conforme abaixo:

a. Pólo Interno:

i. lado interno: relação interna de produção mais arcaica;

ii. lado externo: nova forma de organização produtiva em vias de incorporação das mudanças do lado interno do pólo externo;

b. Pólo Externo:

i. lado interno: face por meio da qual, o país interage com o exterior;

ii. lado externo: o próprio movimento externo do centro do sistema capitalista.

A partir de então, Rangel construiu sua análise da dualidade brasileira afirmando que todas as instituições e categorias do desenvolvimento apresentavam uma natureza dual, conversando com o exterior e sofrendo suas influências. Não é surpresa, portanto, que sua proposta de intervenção busque em algum momento romper com este estado de coisas a partir de dentro. No entanto, sua visão a partir das influências do exterior voltou para si como a face de um determinismo que representava a continuidade, e não a ruptura, do status quo vigente. Novamente nas palavras de Maria Malta:

\footnotetext{
A dinâmica da mudança é sempre a incorporação do externo para dentro. O que pressupõe, em última instância, que o movimento detonador do processo de mudança vem sempre de fora. Essa visão evidencia o grau de dependência que Rangel identificava nas dualidades brasileiras. Por isso, também, muitos o chamavam de "determinista". (idem, p. 8).
}

Seguindo no raciocínio rangeliano, é preciso compreender a lógica da estrutura do país para avançar nas proposições de um projeto de desenvolvimento. O Brasil é um país com um 
pacto federativo baseado no federalismo, ou seja, não dá para pensar e agir no país por meio de políticas públicas dissociadas da ligação entre o local, o regional e o nível federal.

As elites brasileiras são excessivamente líquidas (entesouradas no mercado financeiro) e ancoradas na posse da terra - rural e urbana; uma elite rentista e patrimonialista. Essa elite utiliza a posse da terra para obter renda e não para produzir, com configuração de fenômenos como: o arrendamento de terras; terras improdutivas; imóveis alugados; recursos aplicados no mercado financeiro; remessa de recursos para o exterior, etc. Os efeitos dessa situação são a falta de terra no campo para produzir, configurando por um lado terras altamente caras e produtores resultantes também muito caros, e por outro lado um grande déficit habitacional convivendo com grande ociosidade de moradia nas cidades.

A observação e constatação dessa realidade define o que vem a ser os pólos de ociosidade: recursos adormecidos que precisam ser mobilizados para pólos de anti-ociosidade. Como pólos de anti-ociosidade, podemos citar a aplicação dos recursos ociosos em: educação, infra-estrutura, saúde, mobilidade urbana, saneamento básico e diversos outros setores constantes no projeto do país para o desenvolvimento de longo prazo. Segundo Rangel, quem decide no Brasil são as elites e a base da sociedade civil não é ouvida. Daí sua preocupação na construção de um novo modelo de planejamento e decisão centrado em um Estado forte, mas respeitando as regras da economia de mercado.

A questão da posse da terra no Brasil é um problema agudo de marginalização das camadas mais pobres da sociedade. Quem não tem a posse da terra e de moradia, fica 'solto' no mundo. Daí, a migração para as grandes cidades. Temos, no país, capitais e terras ociosos e uma população destituída e itinerante. O excesso do latifúndio a constituição de mercados locais e de um capitalismo regional e urbano de consumo lastreado na produção e não apenas no crédito. A destituição da propriedade em prol dos latifúndios e da concentração (de terra e de capitais) reforça o afastamento das classes e nos condena ao subdesenvolvimento e à exclusão.

Outra faceta desse tipo de concentração é que o mesmo impossibilita o capitalismo de avançar no país. Como o rentista que adquire terras não conhece da agricultura, por exemplo, o mesmo não empreenderá esforço algum na construção de estruturas eficientes para a distribuição de riquezas e adensamento do capitalismo, como: a construção de armazéns para a produção; estruturas de serviços para a agricultura; logística de transporte para escoamento da produção; modernização e melhorias de produtividade na agricultura e na indústria; fortalecimento dos mercados, etc. A economia do projetamento, como veremos mais adiante, representa uma saída para a construção de alternativas que liguem o que está ocioso dos segmentos carentes de investimento no país. 


\section{O PROCESSO DE DESENVOLVIMENTO E A PERIFERICIDADE}

Segundo o professor Elias Jabour, o desenvolvimento econômico corresponde à expansão da divisão social do trabalho, da produtividade e da economia de mercado. Só existe desenvolvimento - em um dado período histórico - quando existe expansão da economia de mercado como causa e consequência do desmonte da economia natural e/ou da subsistência. O desenvolvimento está limitado pelo estado da técnica vigente e por entraves institucionais, como a base econômica e a superestrutura (estrutura de Estado e o setor privado). Estes aspectos são levados em consta em toda a argumentação rangeliana: é preciso haver uma mudança profunda na estrutura do sistema econômico vigente e na estrutura normativa, com a criação de novas instituições que possam dar segurança jurídica ao novo processo de desenvolvimento de tipo diferenciado, com forte participação do Estado em seu planejamento e execução com o setor privado.

O processo de desenvolvimento, para Rangel, tem forte influência de componentes políticos. Diante disso, ele acreditava na necessidade de um Estado forte e capaz de subverter a lógica do desenvolvimento desigual e da necessidade do planejamento não como um fim em si mesmo, mas sim como um imperativo da história, já percebido inclusive por países capitalistas centrais.

Um dos aspectos importantes do modelo de desenvolvimento brasileiro, segundo Rangel (e citando Jabour), é a sua perifericidade. Historicamente obedecemos a estímulos externos com efeitos tanto sobre a alocação de recursos quanto na produtividade do trabalho e, principalmente, nas mudanças na superestrutura. E este movimento é puxado pelos ciclos longos de Kondratiev: nas fases ascendentes nos inserimos plenamente na economia internacional e nas fases descendentes, nos concentramos no esforço de substituição de importações. Ainda dentro dessa lógica da perifericidade, somos importadores natos de tecnologias - o que remete à crítica do determinismo da tese de Ignacio Rangel.

A intermediação financeira teria o papel de transferir recursos ociosos para locais de "antiociosidade" na economia. Exemplo disso seria a transferência de recursos aplicados no mercado financeiro para investimentos na infra-estrutura do país. Da mesma forma, o setor privado pode ser chamado a contribuir com o processo de desenvolvimento através da utilização de sua acumulação em prol do desenvolvimento do país. Ou, de outro modo, seria chamado a contribuir com a alocação de seus recursos na produção e não na acumulação pura e simples de capital.

\section{CRIANDO ESPAÇOS DE APLICAÇÃO DE RECURSOS OCIOSOS}

Há que se considerar que a baixa taxa de investimentos na economia brasileira (algo em torno de $18 \%$ do PIB) é insuficiente para a promoção do desenvolvimento de longo prazo. 
Diversas correntes da economia defendem que este percentual suba para a casa dos $25 \%$ do PIB para que o país concentre condições objetivas para uma nova fase de desenvolvimento. No entanto, dificilmente se chegará à casa dos $25 \%$ do PIB com uma política que combina estabilidade monetária e combate à inflação; além das restrições de financiamento do tesouro, do endividamento público interno e do endividamento externo.

Faz-se necessário a criação de novas formas de financiamento do desenvolvimento que combine a utilização do mercado financeiro com o grande capital privado nacional para fazer face aos recursos necessários a este novo projeto. Assim, o financiamento ao desenvolvimento brasileiro não mais se limitaria aos tradicionais caminhos do financiamento do desenvolvimento econômico pela via do Tesouro ou do endividamento externo. A formação dos novos conglomerados de financiamento seria a conjugação do poder do Estado com a mobilidade do setor privado, tanto nacional quanto estrangeiro. As concessões de serviços públicos (PPPs e privatizações) seriam formas alternativas para a concretização desse novo projeto.

Porém, há que se ter em mente que a criação dessas condições novas de financiamento do desenvolvimento, exige uma nova estrutura institucional que demanda coesão social e política. O momento atual pelo qual o país está passando parece não ser o mais indicado para um movimento desta envergadura. É possível que o momento seja adiado, mas o fato é que a história reservou uma nova frente de planejamento do desenvolvimento de longo prazo para os países da periferia. Esta nova frente de desenvolvimento está ancorada na estabilização da economia e nos pilares da democracia e das regras de mercado. A operacionalização deste novo desenvolvimento está alicerçada na técnica do projetamento e também no processo de industrialização de um novo tipo, qual seja, uma industrialização preocupada com as características regionais e locais, suas dificuldades e sua interligação com a federação através dos mercados.

\section{A ECONOMIA DO PROJETAMENTO}

Pôr em marcha uma nova proposta de desenvolvimento requer a utilização de técnicas que afastem das decisões de investimento, as influências políticas predatórias e desprovidas de aspectos científicos de planejamento.

Projetar não significa inventar novas soluções mirabolantes, mas encaminhar, dar continuidade e fechamento a projetos que estão em andamento. Não há nada pior que projetos pela metade, que consomem recursos e não atendem ao fim ao qual foram pensados. 
É importante sermos criativos, mas pragmáticos. A inovação e a criatividade podem se coadunar com a noção de projetamentorageliana. Podemos transformar a realidade e dar novas cores ao que já está em marcha.

Os gestores atuais do Brasil têm pouca sensibilidade com a questão espacial. Não são afeitos ao processo de planejamento regional. Espaço e território não estão postos à mesa com a visão ampla de inclusão das idiossincrasias das populações locais. É importante planejar o Brasil regionalmente, não de Brasília e nem do exterior. É vital pensar o Brasil com sensibilidade espacial-territorial e sua articulação com o exterior, mas a partir de dentro, levando em consideração as suas particularidades.

\section{A TÉCNICA DO PROJETAMENTO E O PAPEL DO ESTADO NESTE PROCESSO}

Elaborar, justificar e executar projetos (de desenvolvimento) no Brasil, sempre foi tarefa de engenheiros que, para tal, estudavam em suas formações, noções gerais de economia. Em que pese a importância das duas formações e a riqueza que se pode chegar com o conhecimento das duas ciências, Ignácio Rangel alertava para o fato de que sempre que se tentou uma simbiose entre as duas, "a personalidade do físico da natureza predominará sobre a do físico da sociedade, ou vice-versa" (RANGEL, 2005, pp. 356). Para resolver este conflito, o caminho é transferir a responsabilidade dos ombros de uma só pessoa para uma equipe.

Os engenheiros ficavam com a missão de alocar recursos internos das empresas de maneira eficiente, enquanto que os economistas começaram a atuar através do estudo de mercado. As maiores dificuldades encontradas pelos técnicos neste momento era sua relação com o empresário, notadamente aquele das regiões menos desenvolvidas do país, onde os negócios empresariais não contavam ainda com a impessoalidade necessária. A figura do "olho do dono" estava sempre presente nas decisões empresariais, forçando engenheiros e economistas a dedicarem um tempo a mais de suas atividades ao processo de convencimento do dono do negócio.

O advento da entrada do Estado no processo de planejamento da economia é tido, por Rangel, como o surgimento de um novo tipo de "empresário". A intervenção estatal no Brasil reside em projetos de criação de grandes unidades, tecnicamente complexas, onde 'o erro inicial se reflete durante toda a vida do projeto, porque se encarna em rígidas estruturas de custo'.

Nada mais atual do que a crítica de Rangel ao Estado brasileiro, como abaixo:

O Estado brasileiro não podia gerir melhor os seus negócios do que o empresário provado brasileiro. A experiência demonstra, com efeito, que sua gerência é pior ainda, porque seu "olho do dono" não tem as virtudes que pode ter o empresário privado. Sua intuição é pobre, porque lhe falta o trato cotidiano com os mercados de fatores e produtos do pequeno fabricante, e porque não está sujeito à inapelável 
sanção de falência, em caso de erro. Quase sempre, pode transferir seus prejuízos para os ombros do público contribuinte. (RANGEL, Obras Reunidas, vol. 1, pp. 357).

A intervenção do Estado de forma ampla na economia traz um agravante significativo que precisa ser levando em conta. "Quando ele manda construir uma escola, uma estrada, uma ponte, um posto de saúde, intervém ao mesmo tempo como produtor e consumidor. A rigor, é ele mesmo - em nome da sociedade - o seu mercado, isto é, os mesmos órgãos deliberativos do Estado que, como consumidor, decidem comprar o serviço, alocam os recursos para a produção, exatamente como a dona de casa que compra gêneros para a família. $\underline{\text { O estudo de mercado é tão }}$ pouco necessário num caso como no outro". (idem, pp. 358; grifo meu.)

Rangel descreve de maneira pormenorizada as dificuldades de se avançarem os projetos no país (para a promoção do desenvolvimento) - além das dificuldades relatadas acima a respeito da intervenção Estatal - por conta da formação do técnico responsável pelos mesmos - se engenheiro ou economista. Além dessas duas figuras, outros dois atores são trazidos à tona: o jurista e o contador. Como não necessariamente essas pessoas se encontram em todas as fases do projeto, não raro temos descontinuidades ou projetos mal concebidos, mal justificados e, consequentemente, mal executados. Os resultados não podem ocorrer como planejado, por óbvio.

Uma alternativa para isso seria a constituição de um órgão colegiado, um grupo de projetos, com habilidades multidisciplinares, que atuem juntos do início ao fim dos projetos. Nas palavras do próprio Rangel:

\begin{abstract}
Do ponto de vista prático, a solução consiste em criar um órgão colegiado, uma equipe, que possa, por aproximações sucessivas, assegurar o tratamento unitário à matéria. Cada hipótese será, assim, simultaneamente testada por todos os ângulos, modificada e aprovada ou abandonada afinal. Noutros termos, serão aferidos simultaneamente os efeitos da hipótese sobre o custo e o benefício, no curto e no longo prazos, sobre a posição financeira da empresa, sua estrutura jurídica, etc. A seu tempo, as equipes poderão ser enriquecidas com as contribuições de novos especialistas, tais como o técnico de organização, o técnico de administração, o estatístico, etc., sem falarmos em numeroso pessoal auxiliar. (ibidem, pp. 361)
\end{abstract}

O que Rangel se refere assemelha-se ao processo de planejamento e profissionalismo das administrações públicas como se pode observar em diversas cidades da Espanha e de outros países. Na Espanha - nas cidades de Cullera, Valência, Gandía, Benidorm - a figura do gestor municipal foi regulamentada enquanto carreira e delegada a profissionais com perfil para o cargo. Assim, as atividades relativas ao planejamento do desenvolvimento são direcionadas a profissionais gabaritados e com conhecimento para tal, inexistindo o expediente do apadrinhamento político. A continuidade dos projetos fica garantida, bem como a qualidade dos mesmos. É possível montar uma equipe de profissionais técnicos competentes que discutirão de maneira interdisciplinar todos os aspectos relativos ao desenvolvimento de determinada região. 
Este trabalho não exclui, é claro, a decisão política em sentido amplo - seja do empresário privado, seja do Estado. Mas esta deve ficar, no essencial, reduzida entre a escolha entre as diversas alternativas formuladas e testadas no nível técnico, evitandose assim a improvisação habitual. (RANGEL, 2005, pp. 362).

Um pensamento tão claro amplia o espaço de concertação do desenvolvimento e cria condições objetivas para a sua posta em marcha. Não resta dúvida sobre as categorias essenciais de um projeto, quais sejam seu custo e seu benefício para a sociedade. O que não é custo é benefício! Nas palavras objetivas de Rangel:

O projetamento é, ao mesmo tempo, macro e microeconomia; é teoria e é prática; é apreciação do particular no geral, do concreto no abstrato, e verificação do abstrato no concreto. Do ponto de vista da engenharia, é, simultaneamente, aplicação dos conhecimentos anteriores e formulação de novos problemas cuja solução, eventualmente, enriquecerá aquele acervo de conhecimentos, libertando as energias criadoras do engenheiro. O engenheiro aprenderá a desvencilhar-se da tirania do manual e dos prospectos do fabricante de equipamento. Será convidado a criar, a inventar, como tarefa de rotina (idem).

\section{O DESENVOLVIMENTO TERRITORIAL, INCLUDENTE E PARTICIPATIVO COMO REFORÇO AO PENSAMENTO RANGELIANO}

No processo de desenvolvimento territorial, participativo e inclusivo, não há como realizar análises ou implementar políticas que separem o ser humano e a ação humana de seu espaço e evolução histórica. A tentativa de dissociar as categorias inerentes ao processo (desenvolvimento endógeno, participação política do homem em seu habitat, processos de aprendizagem e inovação, história, cultura e sociedade) fragiliza a ação pródesenvolvimento e induz a uma ação parcial.

Atuações por projetos, setores, economia ou combinações de poucas das categorias de intervenção são exemplos de fragilização das intervenções no desenvolvimento territorial. Ações como essas são armadilhas e modismos superficiais que ignoram algumas escalas territoriais, pondo-as em oposição e, geralmente, as reduz ao binômio local-global.

Conforme salientou Milton Santos (1978, 1979, 2001 e 2005), é necessário não ignorar que o território - como espaço político, social e economicamente construído - corresponde ao palco onde se realizam as atividades criadas por meio da herança cultural que o povo ocupa; além de construir também uma fração do espaço local articulada ao regional, nacional e mundial.

Políticas de desenvolvimento que ignoram a dimensão territorial acabam inexoravelmente contribuindo para agravar as exclusões e disparidades econômicas, sociais e políticas. O Brasil passou por isso nas décadas de 1980 e 1990 com a influência da globalização agindo diretamente nas realidades locais de estados e municípios. A influência deste tipo de pensamento como forma de analisar a realidade e construir políticas de intervenção colocou, por exemplo, a região Nordeste afastada dos processos de desenvolvimento inclusivos ainda hoje sentidos em seu interior. 
Conforme alertava Furtado:

\begin{abstract}
a globalização não leva de forma alguma à adoção de políticas uniformes (...) As disparidades entre as economias são devidas não apenas aos fatores econômicos, mas, e isto é mais importante, à diversidade nas matrizes culturais e particularidades históricas (FURTADO, 1998, p. 74).
\end{abstract}

Ao analisar uma região em sua inteireza procura-se compreender as dinâmicas históricas e culturais que trouxeram sua população à situação em que se encontram na atualidade. As configurações estruturais, os aspectos inovativos, as limitações e potencialidades ambientais explicam muito sobre sua realidade. Mas, sobretudo, a ação política e social de sua população e da estrutura de poder que se cristalizou em seu entorno nos dá respostas para o que enxergamos na atualidade.

Neste ponto, vale a pena inserir brevemente a concepção de outro pensador do desenvolvimento com vastas preocupações acerca do desenvolvimento como um fenômeno complexo e multifacetado. Ignacy Sachs (ou Ignacio, como gosta de ser chamado), é um economista polonês(Varsóvia, 1927), naturalizado francês, que morou no Brasil no período pósII Guerra Mundial. Também é referido como ecossocioeconomista, por sua concepção de desenvolvimentocomo uma combinação de crescimento econômico, aumento igualitário do bem-estar social e preservação ambiental.

Sachs, como Rangel, preocupa-se com a questão do desenvolvimento em sua totalidade, trazendo para o centro do palco a figura do ser humano e de seu hábitat. Seu pensamento se cruza com o de Rangel em diversos aspectos, como o planejamento do desenvolvimento, as questões relativas à inclusão produtiva e a distribuição de renda de maneira igualitária, o trabalho decente e também com questões relativas ao equilíbrio do planeta terra enquanto um sistema único que devemos preservar.

É de se imaginar como seria um encontro entre os dois Ignacios! Para nosso conforto ficou o legado do Rangel e ainda o trabalho forte do Professor Sachs neste planeta, em prol de um desenvolvimento mais justo.

\title{
O CONCEITO DE DESENVOLVIMENTISMO COMO ALTERNATIVA AO ROMPIMENTO COM O SUBDESENVOLVIMENTO
}

A construção do conceito de desenvolvimentismo cria as condições de articulação do pensamento de Ignacio Rangel rumo a um fim no processo de ruptura com o velho e criação do novo. O termo desenvolvimentismo organiza as condições necessárias para o novo conceito e ilumina as questões de método e de aplicação de seu ferramental operacional.

Faremos algumas apresentações de definições até chegarmos à definição de Pedro Fonseca, que construiu o conceito de forma metodológica que abrange a totalidade dos aspectos 
inerentes a este processo. Inicialmente, gostaríamos de trazer à tona a definição de Bielschowsky sobre o que vem a ser o desenvolvimentismo, sob o aspecto da ideologia:

\begin{abstract}
(...) desenvolvimentismo como a ideologia de transformação da sociedade brasileira definida pelo projeto econômico que se compõe dos seguintes pontos fundamentais: (a) a industrialização integral é a via de superação da pobreza e do subdesenvolvimento brasileiro; (b) não há meios de alcançar uma industrialização eficiente e racional através da espontaneidade das forças de mercado, e por isso, é necessário que o Estado planeje; (c) o planejamento deve definir a expansão desejada dos setores econômicos e os instrumentos de promoção dessa expansão; e (d) o Estado deve ordenar também a execução da expansão, captando e orientando recursos financeiros e promovendo investimentos diretos naqueles setores em que a iniciativa privada for insuficiente. (BIELSCHOWSKY, 1988, p.7).
\end{abstract}

A partir desta nota de abertura, podemos listar elementos comuns à construção do conceito de desenvolvimentismo:

a. A existência de um projeto deliberado ou estratégia tendo como objeto a nação e seu futuro. Esta pode ser associada, com certa licenciosidade, a projeto nacional, desde que não se entenda por isso repulsa ao capital estrangeiro nem rompimento com a ordem internacional, mas simplesmente a nação como epicentro e destinatária do projeto;

b. A intervenção consciente e determinada do Estado com o propósito de viabilizar o projeto, o que supõe atores aptos e capazes de executá-lo no aparelho do Estado e com respaldo social e político de segmentos e classes no conjunto da sociedade;

c. A industrialização, como caminho para acelerar o crescimento econômico, a produtividade e a difusão do progresso técnico, inclusive para o setor primário.

O desenvolvimentismo seria uma resposta para superar o subdesenvolvimento, através da melhoria dos indicadores sociais. O desenvolvimentismo passa a ser um guia de ação cuja ideologia concebe o desenvolvimento não mais apenas como meio para atingir um fim, mas como um fim em si mesmo, pois incorpora em seu conceito os próprios valores perseguidos. Na prática, o Estado desenvolvimentista típico tenderá a subordinar toda a ação estatal a este propósito, não se restringindo à área econômica (política, meios, fins e institucionais), mas estendendo-a à educação, cultura, saúde pública, leis sociais, meio ambiente, etc. (FONSECA, 2014).

Importante esta noção de desenvolvimentismo como algo maior, mais complexo no processo de evolução das sociedades. Conforme assinala Conceição (2012, p. 119, apud FONSECA, 2014), o processo de crescimento econômico é maior que apenas a intencionalidade deliberada dos planejadores.

Crescimento econômico é complexo demais para originar-se de maneira apenas
intencional. As mudanças institucionais, tecnológicas e sociais devem caminhar simultânea
e articuladamente na direção desse objetivo, o que não é algo historicamente fácil de obter.

Ao se construir o conceito de desenvolvimentismo, não se pode perder de vista que o crescimento industrial e a mudança de modelo, por sua envergadura, exigiram alterações 
institucionais de vulto, maior complexificação do aparelho do Estado e a criação de novas leis, códigos e marcos regulatórios.

Levando em consideração todas essas aproximações, Pedro Cezar Dutra Fonseca propõe a seguinte definição:

\footnotetext{
Entende-se por desenvolvimentismo a política econômica formulada e/ou executada, de forma deliberada, por governos (nacionais ou subnacionais) para, através do crescimento da produção e da produtividade, sob a liderança do setor industrial, transformar a sociedade com vistas a alcançar fins desejáveis, destacadamente a superação de seus problemas econômicos e sociais, dentro dos marcos institucionais do sistema capitalista (FONSECA, p. 60).
}

Sem intervenção, o subdesenvolvimento continua se reproduzindo. Há que se romper o ciclo para a promoção do desenvolvimento (FURTADO, 1998). Para a consecução do desenvolvimentismo há que se reconhecer que existe um problema a ser superado. Desenvolvimentismo é uma política econômica que está a serviço de uma ideologia. O desenvolvimentismo tangencia as categorias: industrialização, projeto nacional e intervencionismo. O desenvolvimentismo busca romper com a pobreza, a baixa produtividade e a exclusão social. Finalmente, podemos dizer que o desenvolvimentismo não é contrário à estabilidade.

\section{O PAPEL DO ESTADO NO PROCESSO DESENVOLVIMENTISTA}

Diferentemente do pensamento liberal, o Estado tem um importante papel no processo desenvolvimentista, como já largamente argumentado acima. No entanto, é mister qualificar que tipo de Estado para que tipo de intervenção estamos falando.

O Estado liberal da teoria econômica tradicional justifica a sua intervenção quando o retorno social do investimento é maior que o retorno privado - reduzindo a probabilidade de investimento do setor privado. Suas atividades principais seriam a limpeza da poluição (correção de externalidades negativas no sistema econômico), os investimentos em projetos de longa maturação (como o saneamento básico) e o financiamento da pesquisa básica. Além disso, caberia ao Estado as funções clássicas de segurança, proteção à propriedade privada, educação, saúde.

Na convergência com a visão rangeliana no tocante à parceria com o setor privado, Mariana Mazzucato propõe um Estado empreendedor, inovador e ágil. Ela propõe que o Estado deve ser chamado a colaborar com grandes desafios socioeconômicos e ambientais, como por exemplo: as questões demográficas, e a economia verde. Mazzucato demanda um tipo de Estado que tenha disposição e capacidade dos agentes econômicos de assumir, por exemplo, o risco e a 
incerteza knightiana ${ }^{1}$ : aquela que é verdadeiramente desconhecida; o que não se pode medir; enfim, um risco que não pode ser calculado!

Este novo tipo de Estado na economia demanda a criação de uma nova profissional e da especialização dos atores públicos. Tem o papel de impulsionar o setor privado no caminho de novas descobertas quando este ainda não está convencido ou não tem verdadeiras condições de promover os investimentos iniciais necessários a grandes descobertas e inovações. Este novo organismo

\begin{abstract}
é um parceiro fundamental do setor privado - em geral mais ousado, disposto a assumir riscos que as empresas não assumem. $O$ Estado não pode e não deve se curvar facilmente a grupos de interesse que se aproximam dele em busca de doações, rendas e privilégios desnecessários, como cortes de impostos. Em vez disso, deve procurar aqueles grupos de interesse com os quais possa trabalhar dinamicamente em sua busca por crescimento e evolução tecnológica. (MAZZUCATO, 2014, p. 29).
\end{abstract}

\title{
CONCLUSÃO
}

É inegável a oportunidade do momento histórico brasileiro e mundial para o planejamento do desenvolvimento. A despeito de todos os apelos em contrário, o liberalismo assentado exclusivamente nas forças da mão invisível dos mercados, não é suficiente para dar conta de um processo de desenvolvimento inclusivo e de longo curso.

Várias são as razões para esta impossibilidade no Brasil. Por exemplo, podemos citar:

a. O país ainda não rompeu com sua estrutura de poder hierárquico, rentista e autoritário. Os rincões deste país ainda guardam relações anacrônicas de discriminação por cor, sexo, renda e nome de família.

b. Sua estrutura produtiva - apesar de madura em alguns setores - ainda é dependente do exterior e não tem dinâmica própria. Nosso capitalismo provado ainda é incipiente, e seu grau aumenta na medida do afastamento dos grandes centros industriais do país.

c. Nosso processo de industrialização está ainda inconcluso. Carecemos de uma industrialização que incorpore as especificidades regionais e que converse com outras regiões mais dinâmicas através da integração dos elos das cadeias produtivas regionais.

Ao Estado de novo tipo cabe induzir o desenvolvimento e, em alguma medida, até criá-lo e operacionalizá-lo, como parceiro do setor privado. Neste ponto as agências de fomento podem representar na escala regional, este organismo novo, regulado e transparente para a sociedade e para as empresas. Ora, como somente podem investir dentro dos seus Estados de origem, as agências de fomento podem articular parcerias, captar recursos financeiros, promover o fomento, preparar tecnicamente as empresas e até investir diretamente na produção ou no incentivo a novos projetos estratégicos para as economias locais.

\footnotetext{
${ }^{1}$ Incerteza knightiana é atribuída ao economista americano Frank Knight (Universidade de Chiccago), que teorizou a respeito do risco e da incerteza e suas diferenças em termos econômicos.
} 
É preciso mobilizar as forças produtivas e financeiras internas para esta nova aceleração de um projeto de desenvolvimento carente de ser revisitado e retomado. Neste particular, novamente podemos citar as agências financeiras de fomento como um elemento fundamental na articulação do privado com o público, por meio de associações para a produção. Sua forma de atuação regulada traz a segurança institucional necessária para atender a esta nova tarefa. No entanto, estes novos organismos ainda carecem de fundingadequado para fazer sua função de promover os investimentos contra cíclicos e de longo prazo na economia. Também sua gestão deve ser entregue a profissionais de mercado comprometidos com o desenvolvimento e com as regras, normas e leis relativas ao mercado financeiro, a ética e a moral da sociedade.

No entanto, há que se perguntar onde estão as condições políticas e éticas para uma nova arrancada como esta? A nova conjugação de forças pode vir de esforços como os de:

a. Novas instituições e organizações sociais, públicas e de interesse privado. A conjugação dos interesses dessas esferas pode criar - como vem acontecendo em outras partes do mundo espaços de cooperação para o alcance de resultados superiores para toda a sociedade.

b. Uma sociedade mais ciosa de sua responsabilidade enquanto sujeito sobre o objeto de um novo país a ser criado.

c. Compromisso real com o progresso, o trabalho decente, inclusivo, que tenha como valores a moral e a ética; e

d. O foco no interesse comum, em detrimento de desejos mesquinhos de acumulação de coisas.

\section{REFERÊNCIA BIBLIOGRAFICA}

ARÉVALO, A. B. El capital social como recurso de desarrollo. In. Gestión y promoción Del desarrollo local. Universitat de València, 2009. (mimeo).

BARQUERO, A. V. Desarrolloendogeno y globalizacion. Artigo publicado em Madoery, Oscar y VázquezBarquero, Antonio (Eds.). Transformacionesglobales, instituciones y políticas de desarrollo local. Editorial Homo Sapiens, Rosario, 2001.

BAVA, Silvio Caccia, org. Thomas Piketty e o segredo dos ricos. São Paulo: Veneta; Le Monde Diplomatique Brasil, 2014.

BIELSCHOWSKY, R. Pensamento econômico brasileiro: o ciclo ideológico do desenvolvimentismo. Rio de Janeiro: Ipea; Inpes; 1988.

BRANDÃO, Carlos. Ignacio Rangel: intérprete do Brasil. Capítulo a ser publicado em "Patronos do Brasil”. Brasília:Ipea, 2014.

BRESSER-PEREIRA, L. C. Desenvolvimento e crise no Brasil: história, economia e política de Getúlio Vargas a Lula. São Paulo: Ed. 34, 2003.

CAliXTRE, A. B.; BIANCARELli, A.M.; CINTRA, M.A.M. (editores). Presente e futuro do desenvolvimento brasileiro.Brasília:IPEA, 2014.

CHAUÍ, M. Brasil: mito fundador e sociedade autoritária. São Paulo: Editora Fundação Perseu Abramo, 2000.

FERGUSON, Niall. A grande degeneração. São Paulo: Planeta, 2013.

FONSECA, P.C.D. Desenvolvimentismo: a construção do conceito.In Presente e futuro do desenvolvimento brasileiro. Brasília:IPEA, 2014.

FRIEDMAN, Milton. Livre para escolher. Rio de Janeiro: Record, 2015.

FURTADO, C. O capitalismo global. São Paulo: Paz e Terra, 1998. 
MALTA, M. M. (coordenadora, et al). Ecos do desenvolvimento: uma história do pensamento econômico brasileiro. Rio de Janeiro: Ipea: Centro Internacional Celso Furtado de Políticas para o Desenvolvimento, 2011.

MAZZUCATO, Mariana. $O$ estado empreendedor: desmascarando o mito do setor público vs. setor privado. São Paulo: Portfolio-Penguin, 2014.

PIKETTY, Thomas. Capital in thetwenty-firstcentury. Cambridge, Massachussets, 2014.

RANGEL, Ignácio. Obras reunidas (volume 1). Rio de Janeiro: Contraponto, 2005.

Dualidade e ciclo longo. Revista de Economia Política, vol. 4, nº 1, jan-março de 1984.

SENAI. Desenvolvimento, inovação e sustentabilidade: contribuições de Ignacy Sachs. Rio de Janeiro: Gramond, 2014

SANTOS, M. Por uma geografia nova. São Paulo: Hucitec, 1978.

Espaço e sociedade. Petrópolis: Vozes, 1979.

Por uma outra globalização: do pensamento único à consciência universal. Rio de Janeiro: Record, 2001.

Da totalidade ao lugar. São Paulo: Edusp, 2005.

TAVARES, M.C. Acumulação de capital e industrialização no Brasil. Campinas: Editora UNICAMP, 1986. 